\title{
Glutathione binding to dirhodium tetraacetate a spectroscopic, mass spectral and computational study of an anti-tumour compound
}

DOI:

10.1039/c7mt00040e

\section{Document Version}

Accepted author manuscript

Link to publication record in Manchester Research Explorer

Citation for published version (APA):

Wong, D. L., Zhang, A., Faponle, A. S., De Visser, S. P., \& Stillman, M. J. (2017). Glutathione binding to dirhodium tetraacetate a spectroscopic, mass spectral and computational study of an anti-tumour compound. Metallomics, 9(5), 501-516. https://doi.org/10.1039/c7mt00040e

\section{Published in:}

Metallomics

\section{Citing this paper}

Please note that where the full-text provided on Manchester Research Explorer is the Author Accepted Manuscript or Proof version this may differ from the final Published version. If citing, it is advised that you check and use the publisher's definitive version.

\section{General rights}

Copyright and moral rights for the publications made accessible in the Research Explorer are retained by the authors and/or other copyright owners and it is a condition of accessing publications that users recognise and abide by the legal requirements associated with these rights.

\section{Takedown policy}

If you believe that this document breaches copyright please refer to the University of Manchester's Takedown Procedures [http://man.ac.uk/04Y6Bo] or contact uml.scholarlycommunications@manchester.ac.uk providing relevant details, so we can investigate your claim.

\section{OPEN ACCESS}




\title{
Dalton Transactions
}

\section{ARTICLE}

Received 00th January 20xx, Accepted 00th January 20xx

DOI: $10.1039 / x 0 x \times 00000 x$

www.rsc.org/

\section{Glutathione binding to dirhodium tetraacetate: a spectroscopic, computational and mass spectral study of an anti-tumour compound}

\author{
D. L. Wong, ${ }^{a}$ A. Zhang, ${ }^{a}$ A. Faponle ${ }^{b}$, S. de Visser, ${ }^{b}$ and M. J. Stillman ${ }^{a}$
}

\section{See Acknowledgements}

\begin{abstract}
Glutathione ( $\gamma$-L-glutamyl-L-cysteinyl-glycine) is a ubiquitous tripeptide found in all plants and animals. While a major participant in many biological reactions, glutathione has key roles as a metallochaperone, in the reduction of oxidative stress, in the transport of metabolites, and as a cellular thiol source. Here, we report its reaction with, dirhodium(II) tetraacetate $\left(\mathrm{Rh}_{2}(\mathrm{OAc})_{4}\right)$, a compound with anti-tumour properties, using electrospray ionization mass spectrometry and spectroscopic methods to observe in depth the stoichiometries of the final conjugate. Using computational analysis, we provide the first report of the orbital assignments for the resulting glutatathione-bound product. We also explore the competition by GSH for methionine-bound sites on $\mathrm{Rh}_{2}(\mathrm{OAc})_{4}$ as a method for possible protection of its cellular-based therapeutic activity.
\end{abstract}

\section{Introduction}

Intracellular thiols play an important role in metabolism ${ }^{1}$. Nonprotein, sulfhydryl compounds aid in protection against oxidation, as well as in the safe detoxification of harmful or foreign agents through thioether formation ${ }^{1-4}$. This latter property may substantially reduce the efficacy of drug delivery pathways and, subsequently, the success of a drug, which can lead to drug resistance ${ }^{5-11}$. In particular, thiol-based resistance can be deleterious against metal-based chemotherapeutics, as the electron-rich thiolate favor binding to the soft, d-block metals commonly used in such pharmaceuticals, for example, $\mathrm{Pt}(\mathrm{II})$, and $\mathrm{Au}(\mathrm{I})^{10-12}$.

Glutathione (GSH) is a tripeptide that is required in many metabolic cycles and is vital in cellular defence because of its cysteine thiol 1,2, 6, 9,13. Intracellular concentrations of GSH reach $10 \mathrm{mM}$, with its regulation and synthesis tightly controlled ${ }^{2}, 3$. The cysteinyl thiol provides the main ordnance through which glutathione-based protective chemistry acts in guarding the cell against oxidative damage and conjugating metabolites for efflux 2, 3,14. GSH is a common coenzyme and is also heavily involved in metabolic pathways such as glutathione peroxidases, reductases, and glutathione S-

\footnotetext{
a. Stillman Bioinorganic Group, Department of Chemistry, University of Western Ontario, 1151 Richmond Street, London, Ontario, Canada, N6A 5B7. martin.stillman@uwo.ca

b. Address here.

c. Address here.

+ Footnotes relating to the title and/or authors should appear here.

Electronic Supplementary Information (ESI) available: [details of any supplementary information available should be included here]. See DOI: 10.1039/x0xx00000x
}

transferases 2, 6, 7, 15. GSH S-transferases catalyze the combination of GSH with xenobiotic compounds for metabolism and excretion using the highly nucleophilic cysteinyl thiolate ${ }^{2}$. The predominance of GSH in the cell, coupled with its conjugation abilities, means that GSH is a major player in the destructive metabolism of therapeutic compounds, acting through conjugation as a means of drug resistance $3,8,9,11$. Metal-based therapeutic compounds that are vulnerable to thiol chemistry can be structurally altered, and even deactivated, following reaction with intracellular GSH $8,16,17$.

Glutathione reacts with large, soft, metals such as the toxic metals $\mathrm{Cd}(\mathrm{II}), \mathrm{Hg}(\mathrm{II}), \mathrm{Pb}(\mathrm{II})$, and $\mathrm{As}(\mathrm{III}){ }^{18-22}$. This tendency to bind soft metals also extends to the wide range of metals used in therapeutic complexes, for example, $\mathrm{Ag}(\mathrm{I}), \mathrm{Bi}(\mathrm{III}), \mathrm{Pt}(\mathrm{II})$ in cisplatin, and $\mathrm{Au}(\mathrm{I})$ in Auranofin 10, 12, 23-26. A marked increase in glutathione synthesis is often correlated with cisplatin resistance, such as the case in human ovarian cancers $10,27,28$. This type of protective chemistry is the basis for the coadministration of glutathione as a defence against renal toxicity in platinum-based chemotherapies ${ }^{4,14}$. There is evidence that the inhibition of glutathione synthesis reverses cisplatin resistance in some cancer types ${ }^{29-31}$. With an increase in the use of d-block metals as the key components of metallotherapeutic agents, it is critical to understand how this prominent defensive thiolate will interact with biologicallytargeted metal complexes. Such interactions likely reduce the efficacy of these metallodrugs. 
Dirhodium(II) carboxylates and their derivatives are an emerging class of anti-tumour compounds that are described as exhibiting greater potency than cisplatin in vitro ${ }^{32-38}$. However, significantly, with respect to possible cellular chemistry, rhodium(II) carboxylates bind strongly to sulfur containing compounds $32,33,35,37,39-41$. Indeed, the propensity for these rhodium complexes to deplete intracellular thiols makes them especially useful as radiosensitizers ${ }^{42,43}$. Other classes of dirhodium carboxylates, such as the $\mathrm{Rh}_{2}\left(\mathrm{O}_{2} \mathrm{CR}\right)_{4}(\mathrm{R}=$ $\mathrm{Me}, \mathrm{Et}, \mathrm{Pr}$ ), display potent anti-tumour activity that stems from their ability to inhibit enzymes with sulfylhydryl groups in their active sites ${ }^{33}, 34,44$. Dirhodium(II) tetraacetate $\left(\mathrm{Rh}_{2}(\mathrm{OAc})_{4}\right)$ is a bimetallic complex with four bridging acetate ligands bound in an octahedral geometry, with an empty axial site usually coordinated by solvent. This complex is capable of inhibiting DNA polymerase I and RNA polymerase, showing cytotoxic behaviour in vivo against L1210 tumours, Ehrlich ascites, and the sarcoma 180 and P388 tumour lines, as well as exhibiting DNA-binding in a manner similar to that of cisplatin $34,35,45,46$. However, because of the strong, sulfur-binding properties of dirhodium(II) carboxylates, intracellular thiols like glutathione may prevent these rhodium-based therapeutics from reaching their intended target unchanged, especially with the Rh axial bioactive site remaining available. Axial coordination by the strongly binding thiolates will then block the intended activity.

Spectroscopic studies of glutathione binding to dirhodium tetraacetate and related compounds have been reported previously by Jakimowicz et al. ${ }^{47}$ By adding molar equivalents of $\mathrm{GSH}$ to $\mathrm{Rh}_{2}(\mathrm{OAc})_{4}$, the authors surmised that the stoichiometric ratio, $\mathrm{GSH}: \mathrm{Rh}_{2}(\mathrm{OAc})_{4}$, for the final conjugate was 2:1. Unfortunately, optical spectra provide limited information, as the spectral data results from an averaged signal of all the chromophores present. The chemistry that involves coordination to both axial sites would effectively block the dirhodium complex as an effective therapeutic drug. Therefore, the determination of the stoichiometric ratio as a function of GSH is of critical importance in the assessment of dirhodium complexes with therapeutic properties. With the resolving power of Electrospray lonization Mass Spectrometry (ESI-MS), we are able to accurately describe the products formed in reactions of $\mathrm{Rh}_{2}(\mathrm{OAc})_{4}$ with thiolates.

We report here on the products formed following reaction of GSH with $\mathrm{Rh}_{2}(\mathrm{OAc})_{4}$, as well as its competition with methionine-bound $\mathrm{Rh}_{2}(\mathrm{OAc})_{4}$, to probe the fate of the rhodium complex after attack by the thiol and thioether groups, respectively. The reactions were studied in vitro using UVvisible and circular dichroism spectroscopy, and electrosprayionization mass spectrometry (ESI-MS). ESI-MS is especially powerful as a technique for monitoring all possible intermediates formed in a reaction. Computational analysis by time-dependent density functional theory (TD-DFT) show the extent of the overlap of both the linking acetates with the dirhodium $d$ orbitals, and the major influence of the presence of water and thiolate axial ligands on all orbitals of the complex. The DFT results explained the unexpected stoichiometric ratio of the glutathione products. These calculations show that the lowest energy absorption band blue shifts with the addition of strong electron donors. The results described below show that GSH does attack the $\mathrm{Rh}_{2}(\mathrm{OAc})_{4}$, but the stoichiometric ratio is $1: 1$. If the drug complex was protected with the thioether of methionine, the ESI-mass spectra show that GSH would eventually displace that group. However, unlike previously reported reactions with the cysteine-rich, human protein, metallothionein, GSH did not disassemble the complex, leaving it intact, but with one of its reaction sites blocked ${ }^{48}$. These results give detailed guidance for predicting the pharmacokinetics of potential metallodrugs, and provide a mechanism by which the strongly binding GSH may be inhibited.

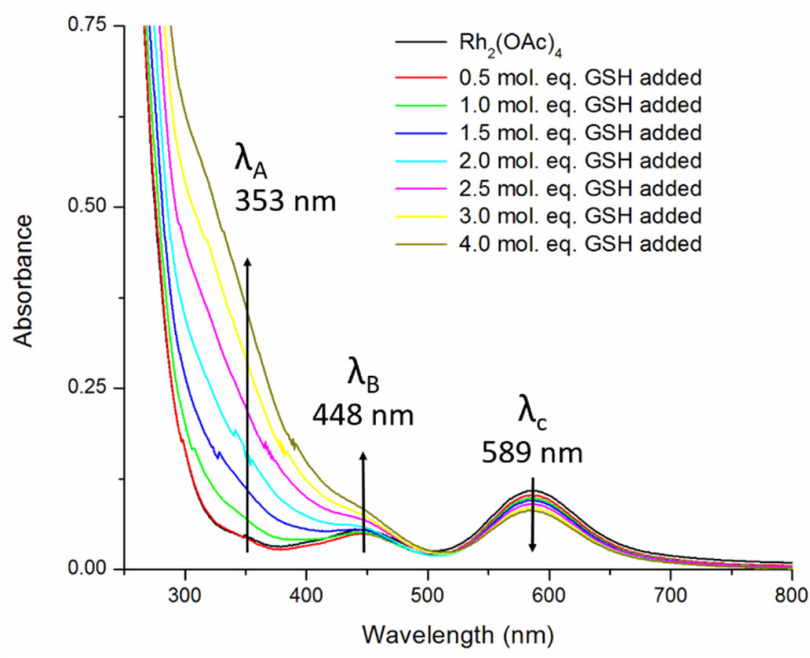

Figure 1 UV-Visible absorption spectra of Rh2(OAc) 4 with aliquots of reduced GSH added.

\section{Results and Discussion}

\section{UV-Visible and Circular Dichroism Spectroscopy following the Colourful Reaction of Glutathione with $\mathrm{Rh}_{2}(\mathrm{OAC})_{4}$}

The reaction of GSH with $\mathrm{Rh}_{2}(\mathrm{OAc})_{4}$ was followed with UVvisible absorption spectroscopy (Fig. 1) and circular dichroism (CD) spectroscopy (Fig. 2). With the introduction of glutathione, a new absorption shoulder appears at approximately $353 \mathrm{~nm}$ (Fig. 1) which has been historically associated with a $S(\sigma)$ $\rightarrow \mathrm{Rh}\left(\sigma^{*}\right)$ ligand-to-metal-charge transfer band (LMCT) characteristic of sulfur coordination to dirhodium carboxylates. A similar band has been previously reported for the spectrum of $\mathrm{Rh}_{2}(\mathrm{OAc})_{4}$ coordinated to the cysteine-rich protein, metallothionein 37, 39, 48. As we will discuss below, this assignment was found to be a mixture of molecular orbitals 
(MO) involving both the Rh-Rh MOs and the thiolate orbitals. The rapid change in spectral properties was observable with the naked eye, as the solution changed from sky blue to golden yellow as the titration progressed. This was expected as a result of the development of absorbance below $400 \mathrm{~nm}$, that was much more intense than the weaker $589 \mathrm{~nm}$ absorption characteristic of the metal-metal-bond. The band at $448 \mathrm{~nm}$ has been historically assigned to $\mathrm{Rh}_{2}\left(\pi^{*}\right) \rightarrow \mathrm{Rh}-\mathrm{O}\left(\sigma^{*}\right)$ transitions of the tetraacetate ligands, which we will expand on with our computational results below. The band at $589 \mathrm{~nm}$ represents the $\mathrm{Rh}_{2}\left(\pi^{*}\right) \rightarrow \mathrm{Rh}_{2}\left(\sigma^{*}\right)$ transition of the metal-metal single bond, which persists throughout the addition of the GSH and,

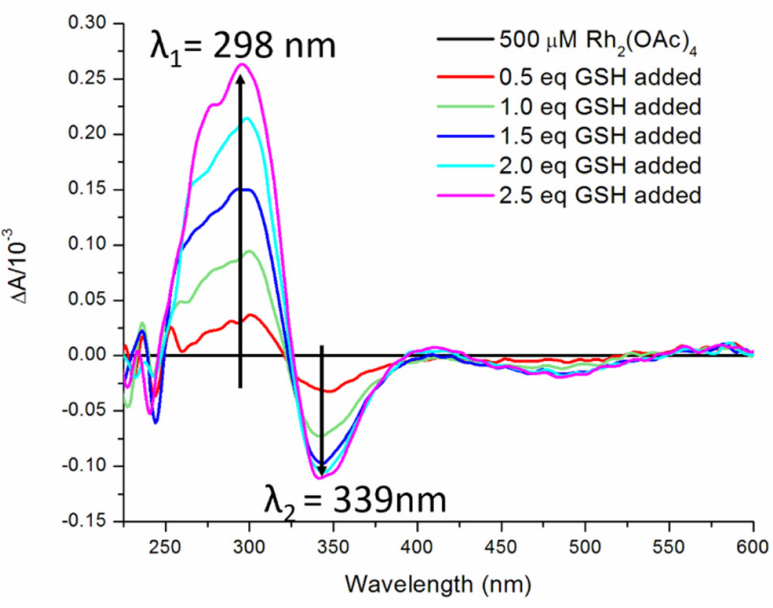

Figure 2 Circular dichroism spectra of $500 \mu \mathrm{M}$ Rh2(OAc) 4 following addition of $0,0.5,1.0,1.5,2.0$, and 2.5 mol. eq. aliquots of $10 \mathrm{mM}$ reduced GSH added.

therefore, shows that the Rh-Rh single metal bond is still intact following thiolate coordination. Only water was used as the solvent for these spectroscopic studies as others like acetonitrile involve coordinating moieties that can drastically alter spectroscopic results.

The circular dichroism spectra shows that $\mathrm{Rh}_{2}(\mathrm{OAc})_{4}$ is achiral, as expected (black line, Fig. 2). However, with the introduction of GSH, two new bands appear, a maximum at $298 \mathrm{~nm}$ (marked as $\lambda 1$ ) and a minimum at $339 \mathrm{~nm}$ (marked as $\lambda 2$ ), with a crossover point between 325 and $330 \mathrm{~nm}$. The development of the strong CD spectrum with the coordination of GSH indicates that a chiral structure is formed upon binding GSH to the dirhodium complex. The arrows show the change in absorption over the course of the titration. Similar CD spectral changes have been reported previously for reactions of GSH with $\mathrm{Cu}(\mathrm{I})$ and $\mathrm{Cd}(\mathrm{II})^{49}$. There was little to no $\mathrm{CD}$ intensity under the metalmetal-bond band at $589 \mathrm{~nm}$. This was not unexpected, as the transition dipoles shown from the computational results below are located away from the chirality introduced by the GSH.

\section{Elucidating Qualitative Spectroscopic Results with Quantitative Analysis by Electrospray lonization Mass Spectrometry}

A preliminary spectra taken at pH 3.0 of GSH with 2 mol. eq. of $\mathrm{Rh}_{2}(\mathrm{OAc})_{4}$ added (with respect to the GSH) show the presence of mono- and di-glutathione adducts. The ESI-mass spectral

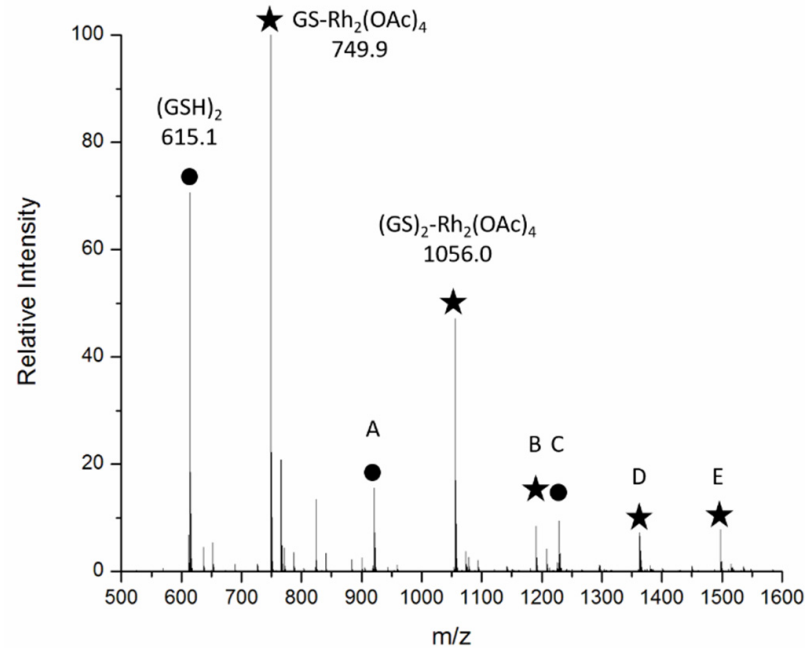

Figure $3 \mathrm{ESI}-$ mass spectra of $600 \mu \mathrm{M}$ reduced $\mathrm{GSH}$ with 2 mol. eq. $\mathrm{Rh}_{2}(\mathrm{OAC})_{4}$ added, at $\mathrm{pH} 3.0$ in deionized water. Taken in the positive ion mode. The spheres identify $\mathrm{GSH}$-related complexes, where $\mathrm{A}$
related complexes, where $\mathrm{B}=\mathrm{D}=$ and $\mathrm{E}=$.

data show that the reaction creates a mixture of species: (i) glutathione polymers (at 615.1, 922.2 (A), and 1229.3 (C) $\mathrm{m} / \mathrm{z}$, Figure 3); and (ii) deprotonated glutathione coordination forming (GS) $\mathrm{Rh}_{2}(\mathrm{OAc})_{4},(\mathrm{GS})_{2} \mathrm{Rh}_{2}(\mathrm{OAc})_{4}$, and possibly a $(\mathrm{GS})_{3} \mathrm{Rh}_{2}(\mathrm{OAc})_{4}$ (at 749.9, 1056.0 (, and 1364.1 (B) m/z, Figure 3). The two most prominent conjugates are those of a single GS -bound complex, GS-Rh $2(\mathrm{OAc})_{4}$, and that of a di-GS2--bound complex, $(\mathrm{GS})_{2}-\mathrm{Rh}_{2}(\mathrm{OAc})_{4}$. With the accuracy of the ESI-MS experiment, it is possible to show that the masses of these two new complexes differ from the sum of the individual components by one and two protons, respectively, indicating that a proton is lost to form the binding moiety. Coupled with the optical spectroscopic data, we identify the cysteine sulfur as being the donor atom from the GSH that is involved. The GS binds to the vacant axial position of $\mathrm{Rh}_{2}(\mathrm{OAc})_{4}$ that is generally coordinated by solvent, as is confirmed by similar studies concerning dirhodium complexes ${ }^{37,39}$.

To test the possibility of conjugation under a more physiologically relevant environment, the reaction was carried out using $500 \mu \mathrm{M} \mathrm{Rh}{ }_{2}(\mathrm{OAc})_{4}$ with $2.5 \mathrm{~mol}$. eq. GSH added in 1 $\mathrm{mM} \mathrm{NH} \mathrm{O}_{4} \mathrm{OAc}$ at $\mathrm{pH} 7.4$, Figure 4. Under these conditions, glutathione remains largely unbound at $308.1 \mathrm{~m} / \mathrm{z}$ in the positive ion mode (further denoted as "+ mode"), and $306.1 \mathrm{~m} / \mathrm{z}$ in the negative ion mode (further denoted as "- mode"). The main $\mathrm{Rh}_{2}(\mathrm{OAc})_{4}$ species observed are the mono-aquated products at $459.8 \mathrm{~m} / \mathrm{z}$ (+ mode), or $458.8 \mathrm{~m} / \mathrm{z}$ in the negative ion mode, where the bis-aquated, mono-acetate and bis-acetate coordinated species are also observed at 476.8, 500.8, and $559.5 \mathrm{~m} / \mathrm{z}$. At a relative intensity of under $10 \%$, the glutathione mono-adduct product is observable at $749.9 \mathrm{~m} / \mathrm{z}$ (+ mode), and $747.9 \mathrm{~m} / \mathrm{z}$ (- mode), corresponding to a complex involving a deprotonated glutathione and the $\mathrm{Rh}_{2}(\mathrm{OAc})_{4}$. Very little diadduct product was observed at $1056.4 \mathrm{~m} / \mathrm{z}$ (+ mode) and 
$1053.0 \mathrm{~m} / \mathrm{z}$ (- mode), both at less than $1 \%$ relative abundance, with virtually none of the possible tri-adduct detected.

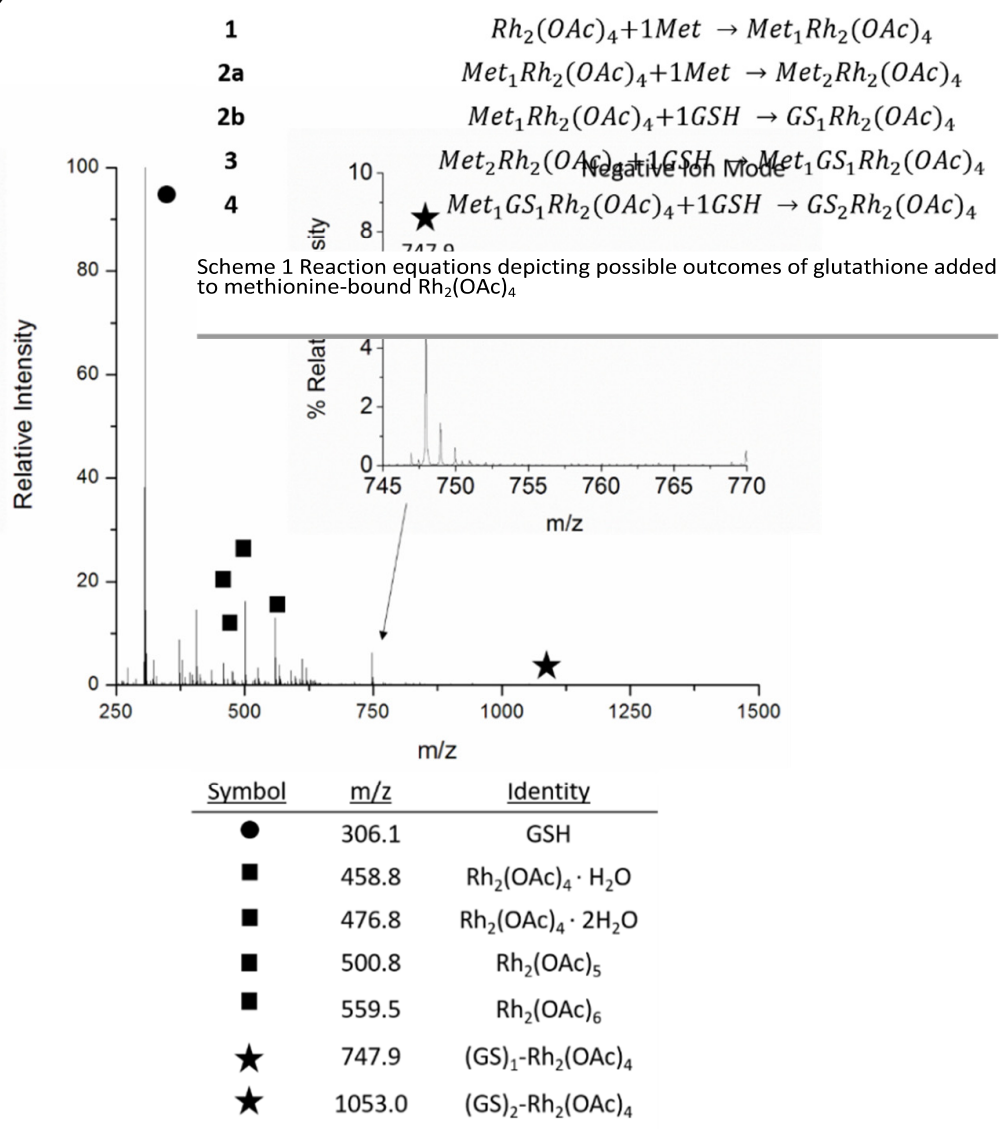

Figure 2. ESI-Mass spectra of $500 \mu \mathrm{M} \mathrm{Rh}{ }_{2}(\mathrm{OAc})_{4}$ with $2.5 \mathrm{~mol}$. eq $500 \mu \mathrm{M} \mathrm{GSH}$ added, recorded in both positive (left) and negative (right) ion mode. The insets show detail of the mono-adduct glutathione-rhodium complex region at near $750 \mathrm{~m} / \mathrm{z}$ for both polarities. The individual peaks are assigned in the tables.

These quantitative results provide evidence for the exact products made in solution, and their relative abundancies viewed in both positive and negative ion mode. It is clear that the strong absorption band reported by Jakimowicz et al. should not be assigned to a 2:1 GSH: $\mathrm{Rh}_{2}(\mathrm{OAc})_{4}$ stoichiometry, rather the product formed in that study was likely $1: 1$. The computational results below provide an interpretation of the appearance of the strong absorption below $400 \mathrm{~nm}$ following coordination with thiolates.

At this point, we have established that GSH binds as a deprotonated peptide to the $\mathrm{Rh}_{2}(\mathrm{OAc})_{4}$ axial positions, forming the mono-adduct at $749.9 \mathrm{~m} / \mathrm{z}$. The combination of mass spectral data and the absorption and CD spectra suggest that the tetraacetate linkers are intact and that the $\mathrm{Rh}-\mathrm{Rh}$ single bond persists. To address the structures of the proposed products, the structure of the singly-bound, and doubly-bound glutathione- $\mathrm{Rh}_{2}(\mathrm{OAc})_{4}$ complexes were constructed in Scigress and their geometries optimized prior to orbital calculations using DFT methods, described below.

Competition by Glutathione for the axially-coordinated Methionine in $\mathrm{Rh}_{2}(\mathrm{OAc})_{4}$ (Met)
Our study with metallothionein suggested axial coordination of the dirhodium core by the cysteinyl thiolates was the initiating reaction prior to complex deconstruction, because the additional cysteines bound in the place of the O-donors of the tetraacetate ligands ${ }^{48}$. As discussed above, cellular resistance can be associated with thiol coordination of the active sites of metallodrugs. Blocking the axial positions of the metallodrug with weak nucleophiles should introduce a defense against cellular resistance due to steric effects impeding the attack by strong nucleophiles. The question arises how best to protect the complex against fast attack by such agents as metallothionein and GSH. The use of a weaker binding ligand, such as the thioether of methionine, may provide this protection. The reaction of methionine and related thioether complexes with $\mathrm{Rh}_{2}(\mathrm{OAc})_{4}$ has been reported by Pneumatikakis et al. and others $37,41,50$. Here we explore the reaction when glutathione is added after methionine is bound to the $\mathrm{Rh}_{2}(\mathrm{OAc})_{4}$. Scheme 1 summarizes the series of reactions that were used to investigate the potential protection offered by methionine (Met) against competition by GSH. First Met was added to the dirhodium complex, and through absorption spectra and ESI-mass spectral data we can determine which of the products actually form: either a single Met binds (Equation 1) or two Met bind (Equation 2a). Next, GSH is added, and again, Scheme 1 shows the possible outcomes: either displacement of one Met bound (Equation 

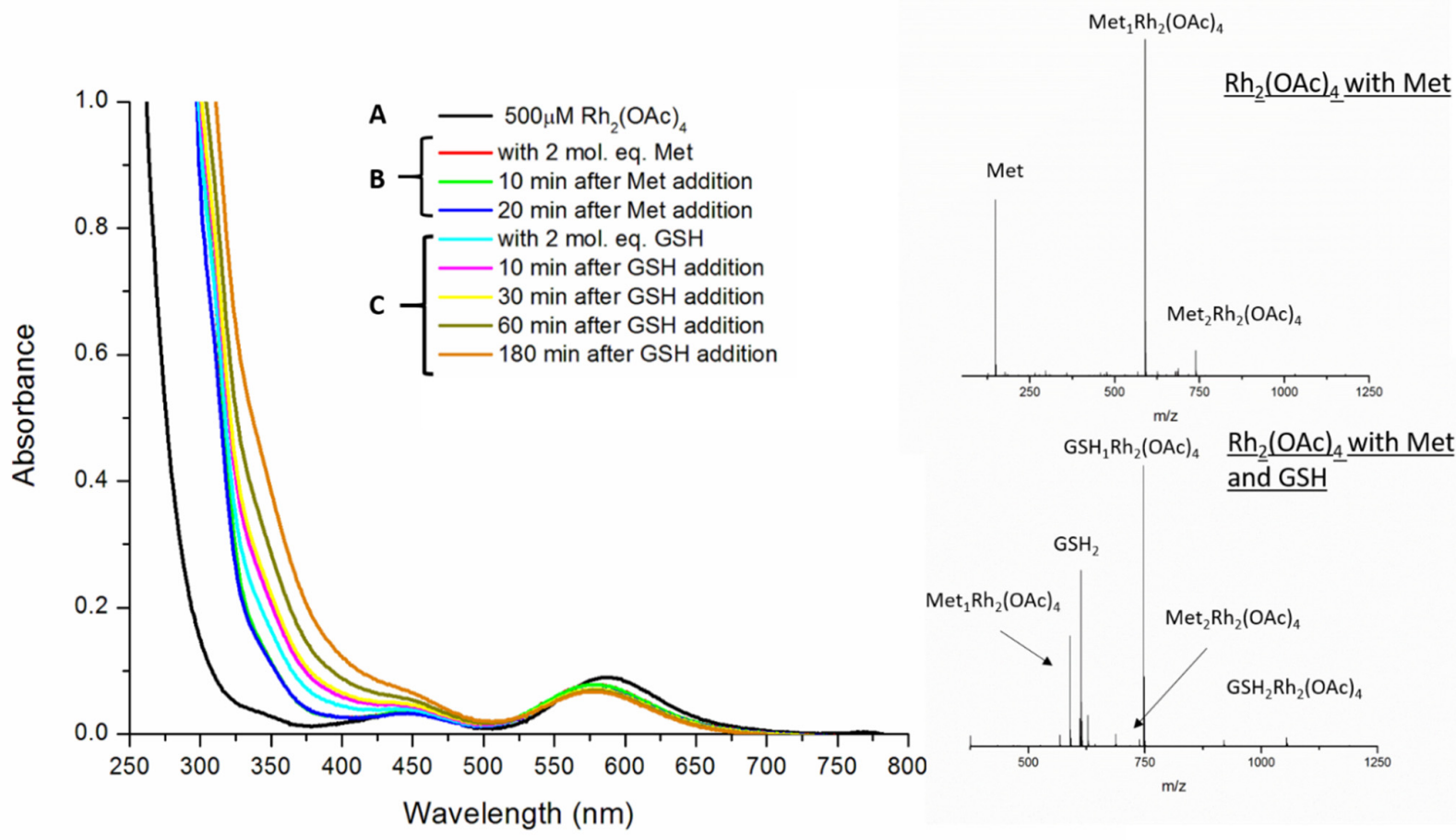

Figure 3 UV-Visible absorption spectral changes (left) following the reaction of an aqueous solution of $500 \mu \mathrm{M} \mathrm{Rh}{ }_{2}(\mathrm{OAc})_{4}$ with 2 mol. eq. of methionine (Met) following 20 min mixing. 2 mol. eq. of glutathione was then added and the spectrum monitored. ESI-MS spectra of the initial methionine bound solution (right, top) and following glutathione addition (right, bottom) were recorded at 20 minutes and 60 minutes after mixing, respectively, in negative ion mode. Notable peaks: Met1 $\left(\mathrm{Rh} 2(\mathrm{OAc})_{4}\right) 589.9 \mathrm{~m} / \mathrm{z}$;

$(\mathrm{Met})_{2}\left(\mathrm{Rh}_{2}(\mathrm{OAc})_{4} 738.9 \mathrm{~m} / \mathrm{z}(\mathrm{GS})\left(\mathrm{Rh}{ }_{2}(\mathrm{OAc})_{4}\right) 747.8 \mathrm{~m} / \mathrm{z} ;(\mathrm{GS})_{2}\left(\mathrm{Rh}_{2}(\mathrm{OAc})_{4}\right)\right.$ 1054.9. There was no evidence for $(\mathrm{Met})(\mathrm{GSH}) \mathrm{Rh}_{2}(\mathrm{OAc})_{4}$ in the expected region of $890-895 \mathrm{~m} / \mathrm{z}$.

$2 b)$, addition to the 2 nd axial position (Equation 3), or complete occupation of both axial positions (Equation 4). The question then is, does Met offer any protection against axial ligation and therefore deactivation by strongly nucleophilic biological thiols, such as GSH and metallothionein, before the drug can reach its eventual target?

Figure 5 shows the absorption and ESI-mass spectra recorded for the reactions outlined in Scheme 1 . The absorption spectrum follows the same trends as described above. The starting spectrum of the $\mathrm{Rh}_{2}(\mathrm{OAc})_{4}$ in Fig $4(\mathrm{~A})$ is the same as in Fig 1 . The addition of 2 mol. eq. of Met results in a slight, but distinct blue shift in the wavelength maximum of the $\mathrm{Rh}_{2}\left(\pi^{*}\right)$ $\mathrm{Rh}_{2}\left(\sigma^{*}\right)$ metal-metal bond band from 589 to $570 \mathrm{~nm}$, indicating as before, that while Met has bound to the complex, the Rh-Rh bond is still intact. The most significant change is the intensification of the band at $350 \mathrm{~nm}$ associated with the thioether coordination ${ }^{39}$ ( $\mathrm{B}$, Fig. 4). The reaction is fast and there is no change after 20 minutes following mixing (B). Now the Met coordination is challenged by addition of $2 \mathrm{~mol}$. eq. of GSH, which results in a slow change in the optical spectrum, with a significant increase in absorbance in the $353 \mathrm{~nm}$ region representing the competition of $\mathrm{GS}^{-}$for the axial position occupied by the methionine (C, Fig. 4). There is a slight red shift in the $580 \mathrm{~nm}$ region that confirms the Rh-Rh bond is still present. Negative ion mode ESI-mass spectra are very important in providing identification of the species present at each step (Fig. 4, inset, top). Following the addition of the Met, the solution measured in the absorption as " $B$ ", is primarily $\operatorname{Met}_{1}\left(\mathrm{Rh}_{2}(\mathrm{OAc})_{4}\right)$ at $589.9 \mathrm{~m} / \mathrm{z}$ as shown in Scheme 1 , equation 1 , with a very small fraction of $M$; et ${ }_{2}\left(R_{2}(O A c)_{4}\right.$ at $738.9 \mathrm{~m} / \mathrm{z}$ formed in equation $2 \mathrm{a}$. Following GSH addition (lines " $\mathrm{C}$ " in the absorption spectra), the negative ion ESI-mass spectrum (Fig. 4, inset, bottom) shows the presence of $\mathrm{GS}_{1}\left(\mathrm{Rh}_{2}(\mathrm{OAc})_{4}\right)$ at 747.8 $\mathrm{m} / \mathrm{z}$ formed in equation $2 \mathrm{~b}$, and also $\mathrm{GS}_{2}\left(\mathrm{Rh}_{2}(\mathrm{OAc})_{4}\right)$ at 1054.9 $\mathrm{m} / \mathrm{z}$ formed in equation 4 . The reactions with GSH were slow, as indicated in the absorption spectra measured over 3 hours, and still possibly not at completion when the mass spectra were measured. We conclude from these results that indeed Met does offer some protection because the displacement reaction is slow, and the binding by the strongly nucleophilic GS impeded. However, from a pharmacokinetic point-of-view, the exact rates in vivo would need to be determined.

\section{DFT calculations provide insight into the stability of the GSH complexes}

As introduced in the Introduction, an accurate $\mathrm{X}$-ray structure of the $\mathrm{Rh}_{2}(\mathrm{OAc})_{4}\left(\mathrm{H}_{2} \mathrm{O}\right)_{2}$ was reported by Cotton et al. in 1971, showing specifically for this present paper the location of the two water molecules on the $\mathrm{z}$-axis defined by the $\mathrm{Rh}-\mathrm{Rh}$ bond ${ }^{51}$. The $\mathrm{Rh}-\mathrm{Rh}$ bond length calculated here for $\mathrm{Rh}_{2}(\mathrm{OAc})_{4}\left(\mathrm{H}_{2} \mathrm{O}\right)_{2}$ is 
A)

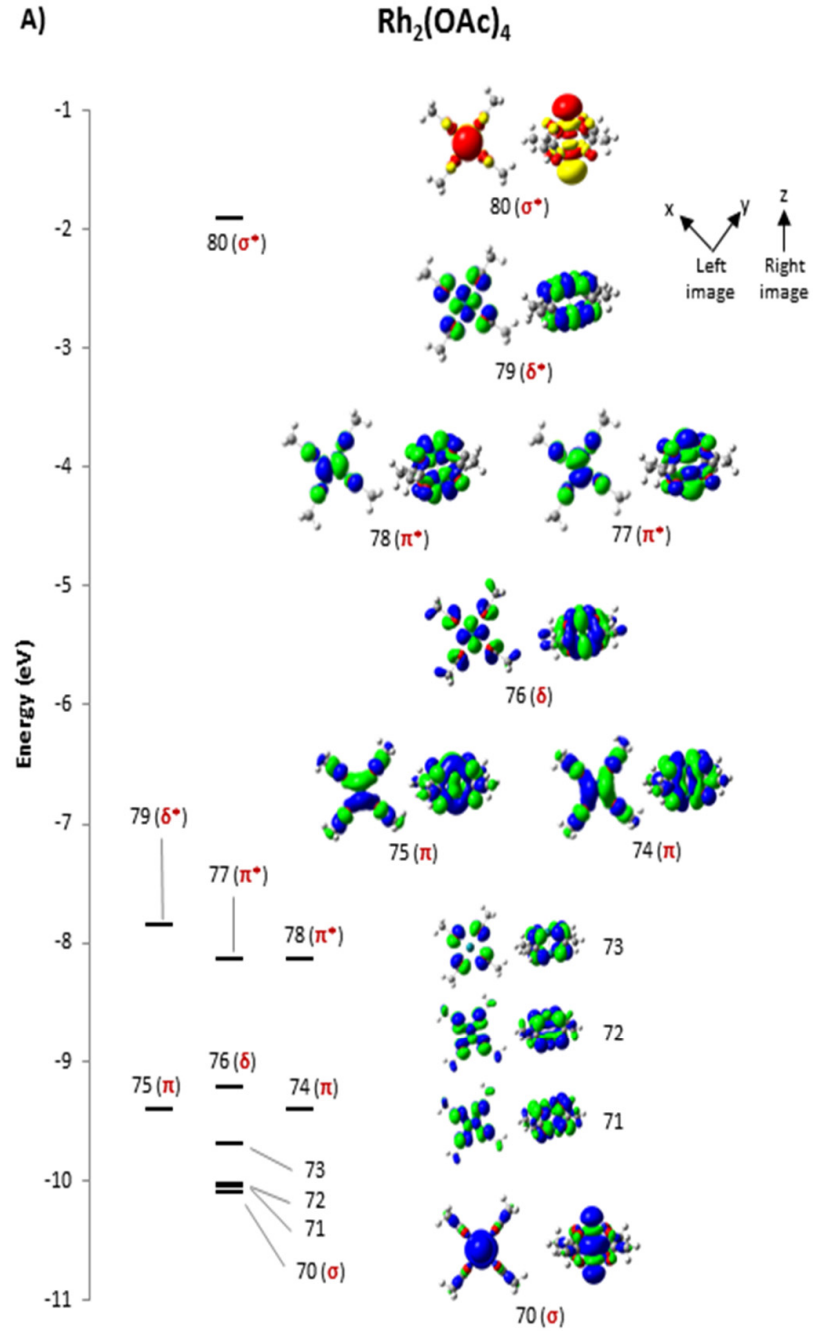

B)

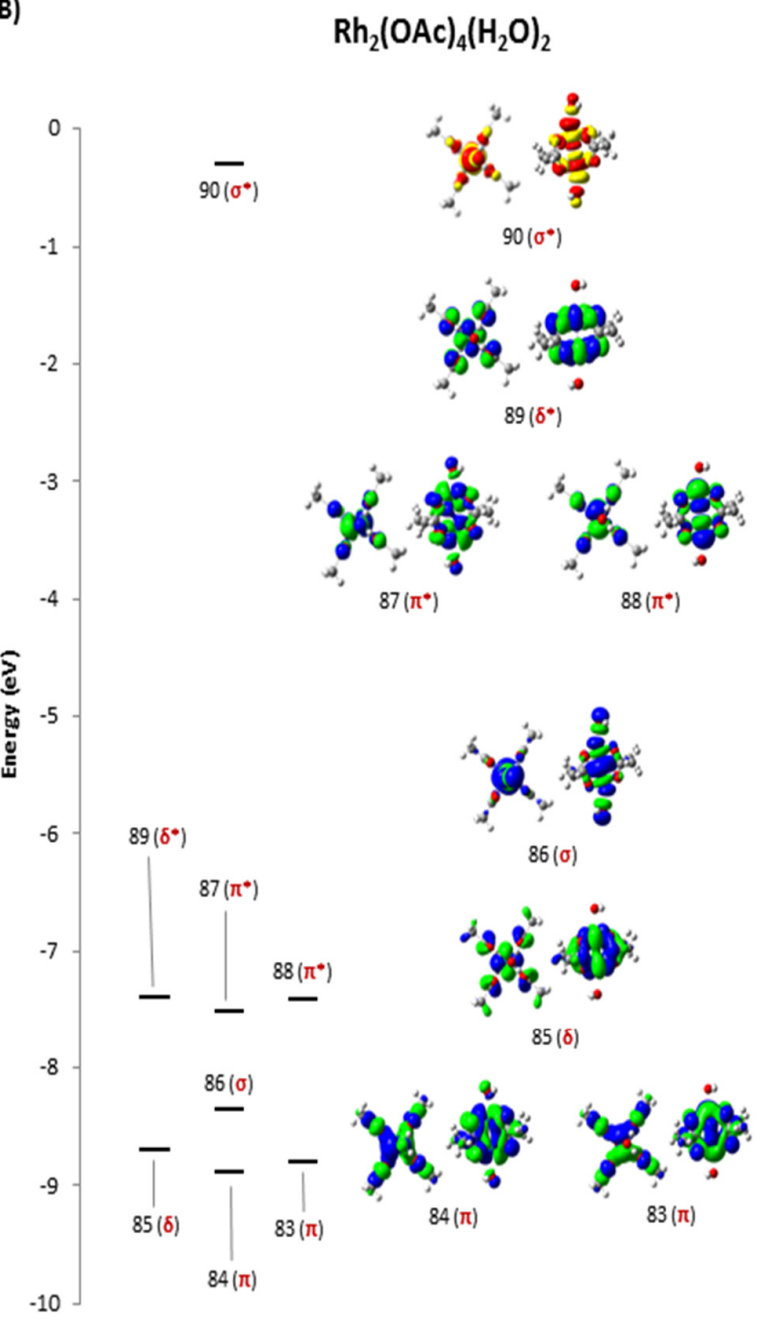

Figure $4 \mathrm{MO}$ energies and isoelectron density surfaces for the MOs that contribute to the visible-near $\mathrm{UV}$ absorption spectra for $\left[\mathrm{Rh} \mathrm{h}_{2}(\mathrm{OAC})_{4}\right]$, and $\left[\mathrm{Rh} \mathrm{h}_{2}(\mathrm{OAC})_{4}\left(\mathrm{H}_{2} \mathrm{O}\right)_{2}\right]$. from DFT geometry optimization calculations with parameters described in the Methods Section. The RhRh core MOs are identified where clear. The isoelectron $\mathrm{Rh}$-Rh bond. Both orientations are easiest to see starting with the $\sigma^{*}$ orbital at the top of the stack of orbitals.

$2.38989 \AA$, which compares well with the reported value of $2.3855 \AA^{51}$. For the results described above, we wanted to examine the electronic structure of the complex in solution and when axially coordinated by GSH. There were three specific question: (i) how extensive is the stabilizing role of the acetate linkers (ii) what is the extent of the disturbance to the Rh-Rh $4 \mathrm{~d}$ based MO structure of the core caused by coordination of the glutathione thiolate ligand, and (iii) can the dramatic colour change from blue to yellow immediately after addition of the thiolates be explained from the calculated absorption spectrum using time dependent-DFT (TD-DFT) methods?

i) The electronic structure of $\mathrm{Rh}_{2}(\mathrm{OAc})_{4}$ and $\mathrm{Rh}_{2}(\mathrm{OAc})_{4}\left(\mathrm{H}_{2} \mathrm{O}\right)_{2}$ to determine the effect of axial coordination by the water solvent.

Axial coordination of the $\mathrm{Rh}_{2}$ core has been the subject of much study ${ }^{37,39,41,43,44,47,50,52-55}$ since the electronic structure for the metal-metal bonded species suggested a single bond, that would leave $5 p_{z}$ or the $4 d_{z}^{2}$ as non-bonding orbitals. The electronic structure leading to the Rh-Rh bond and its bond order, are reflected in the absorption spectrum. Polarized crystal spectra of Martin et $\mathrm{al}^{56}$. (1979, revised slightly by Miskowski et al. in 198457) provided key information in the assignment; first of the lowest energy, visible region band to the $\pi^{*}$ to $\sigma^{*}$ transition, followed at higher energies to mixtures of $\mathrm{Rh}$-based MOs to the $\sigma^{*}$ orbital and also ligand to Rh-Rh core transitions. A more recent report by Futera et al. in 2011 ${ }^{58}$, reported the electron occupancies based on DFT calculations. For completeness in our discussion of the GSH to the axial Rh(II) bond formation, we have included DFT results for the axial ligand-free core, and the $\mathrm{H}_{2} \mathrm{O}$ ligated core in Figure 6 .

Figure 6(A) shows the DFT results for the dirhodium core with just the acetate linkages. The MO order follows the expected sequence with the exception of the increased energy of the $\delta^{*}$ MO (79). The gas phase calculation shows the $\delta^{*}$ lies just above the $\pi^{*}$ MOs (77 and 78). We have labelled the well-known MOs 
A)

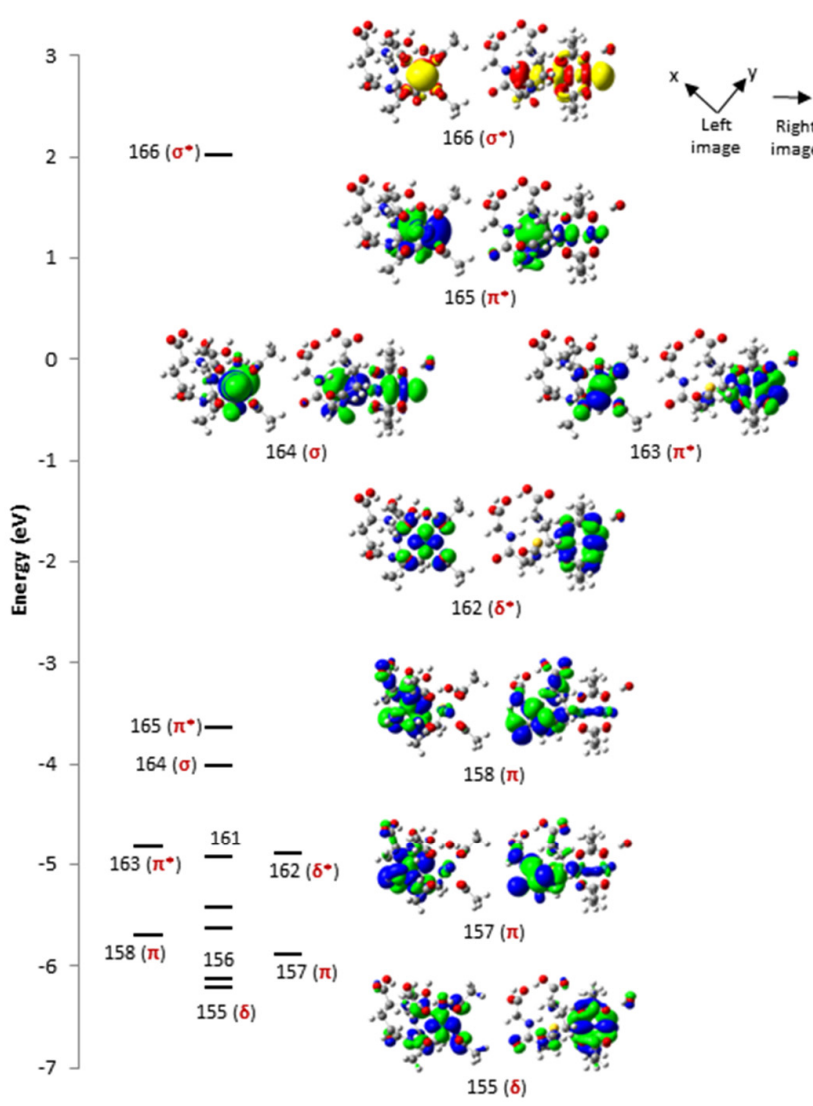

B)

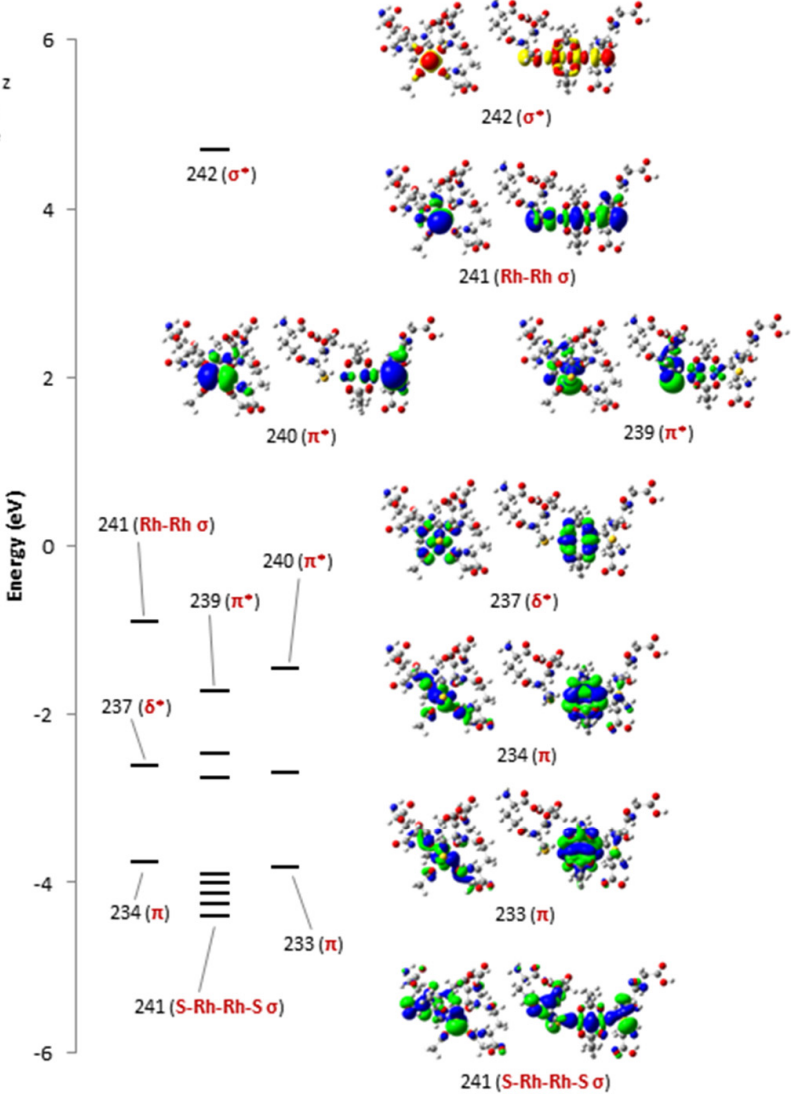

Figure $5 \mathrm{MO}$ energies and isoelectron density surfaces for the MOs that contribute to the visible-near UV absorption spectra for $\left[\mathrm{Rh}_{2}\left(\mathrm{OAC}_{4}\left(\mathrm{H}_{2} \mathrm{O}\right)\left(\mathrm{GS}-\mathrm{S}^{-}\right]^{1}\right.\right.$ and $\left[\mathrm{Rh}_{2}(\mathrm{OAc})_{4}\left(\mathrm{GS}^{-}\right)_{2}\right]^{2-}$ from DFT geometry optimization calculations with parameters described in the Methods Section. The RhRh core MOs are identified where clear. The isoelectron surfaces are displayed in two orientations (left) looking down the Rh-Rh bond so exposing the $\mathrm{x} / \mathrm{y}$ plane and (right)
horizonatlly aligned $\mathrm{Rh}$-Rh bond. Both orientations are easiest to see starting with the $\sigma^{*}$ orbital at the top of the stack of orbitals.

with $4 \mathrm{~d}$ origin (the occupied: $\sigma(70), \pi(74,75), \delta(76), \pi^{*}(77$, $78)$, and $\delta^{*}(79)$ and the lowest unoccupied MO, $\left.\sigma^{*}(80)\right)$. The surface images provide the spatial distribution of these orbitals, showing two orientations. On the left, the view looking down the $\mathrm{Rh}-\mathrm{Rh}$ bond, so this is the $\mathrm{x} / \mathrm{y}$ distribution. On the right, the viewing direction is perpendicular to the Rh-Rh bond, which is aligned vertically to show the axial ligands and acetate linker MOs. Expanded views of all the MO surfaces are presented in the Supplementary Information file. The lowest energy absorption band is predicted to lie at $800 \mathrm{~nm}$ from the $\pi^{*}$ to $\sigma^{*}$ transition (Figure 8)

In aqueous solution the axial positions are coordinated by water (as in the X-ray structures of Cotton et al. (1971) ${ }^{51}$ ) and this represents the species expected for optical and ESI-MS measurements. The $\mathrm{MO}$ energies and surfaces are shown in Figure $6(B)$. The coordination of the two water molecules increases the electron density of the two rhodium atoms, raising the energy of all the MOs in this region. Particularly, the $\sigma \mathrm{MO}(86)$ now lies above the $\delta(85)$ and $\pi(83 \& 84)$. In addition, the energy of the $\sigma^{*} \mathrm{MO}(90)$ is raised roughly $1 \mathrm{eV}$ with respect to that orbital without the ligands (Figure 6A, MO 80). As we see below (Figure 8), the lowest energy absorption band is blue shifted from $800 \mathrm{~nm}$ to $600 \mathrm{~nm}$ for the dihydrate, because the $\pi^{*}$ to $\sigma^{*}$ energy gap increases. Except for the rise in $\sigma(86)$, the ordering does not change, with the occupied $\delta(85)$ and $\delta^{*}(89)$ being located above the respective $\pi$ and $\pi^{*} \operatorname{MOs}(83,84$, and $87,88)$. The surfaces again provide interesting contrasts in the electron distribution for the linking acetates, the two waters, and the two Rh atoms. Symmetry rules mean that the water MOs are only involved in significant overlap with the z-axis $\sigma$ and $\sigma^{*}$ MOs ( $\left.86 \& 90\right)$. More detail is seen in the Supplementary Information.

ii) The electronic structure when thiol is coordinated:

$\left[\mathrm{Rh}_{2}(\mathrm{OAc})_{4}\left(\mathrm{GS}^{-}\right)\left(\mathrm{H}_{2} \mathrm{O}\right)\right]^{-}$and $\left[\mathrm{Rh}_{2}(\mathrm{OAc})_{4}\left(\mathrm{GS}^{-}\right)_{2}\right]^{--}$

The ESI-MS data in Figure 4 show the presence of both the mono- and di-GS2- complexes, although the di-GS ${ }^{2-}$ product is in extremely low abundance. The MO structure for the monoadduct (Figure 7A) shows a significant rise in the energy of all the MOs compared to the bisaquated structure. This is due to the increased density on the Rh atoms from the axial 
A)
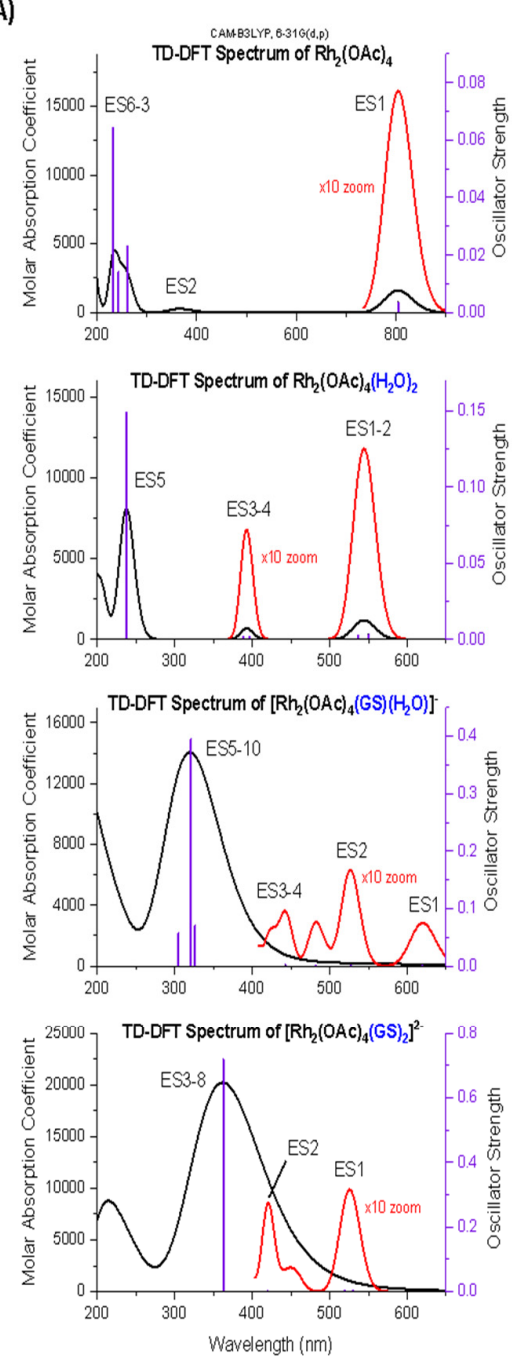

B)

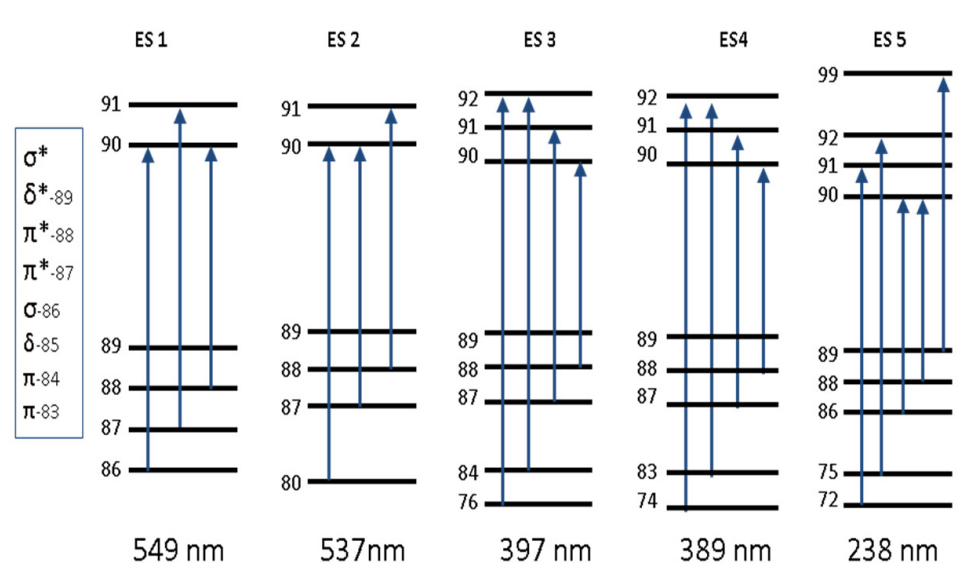

$\mathrm{Rh}_{2}(\mathrm{OAc})_{4}\left(\mathrm{H}_{2} \mathrm{O}\right)_{2}$

Figure 8 Calculated absorption and orbital contributions to the excited states from TD-DFT calculations for $\mathrm{Rh}_{2}(\mathrm{OAC})_{4}$ and the complex coordinated by water and glutathione. (A) Calculated absorption spectra for $\left[\mathrm{Rh}_{2}(\mathrm{OAc})_{4}\right],\left[\mathrm{Rh}_{2}(\mathrm{OAc})_{4}\left(\mathrm{H}_{2} \mathrm{O}\right)_{2}\right],\left[\mathrm{Rh}_{2}(\mathrm{OAc})_{4}\left(\mathrm{H}_{2} \mathrm{O}\right)(\mathrm{GS}-)^{-1}\right.$ and $\left[\mathrm{Rh}_{2}(\mathrm{OAc})_{4}\left(\mathrm{GS}^{-}\right)_{2}\right]^{2}$. The labels "ES1, etc" identify the Excited States for which the oscillator strength for the transition from ESO is greater than 0.001 . The excited states calculated from TD-DFT are tabulated in the Supplementary Files. (B) Orbital participation in the excited states above $230 \mathrm{~nm}$ with oscillator strengths $>0.001$ for $\left[\mathrm{Rh}_{2}(\mathrm{OAc})_{4}\left(\mathrm{H}_{2} \mathrm{O}\right)_{2}\right]$ and $\left[\mathrm{Rh}_{2}(\mathrm{OAc})_{4}\left(\mathrm{H}_{2} \mathrm{O}\right)(\mathrm{GS}-)\right]^{1}$. The detailed contributions are shown in the Table in the Supplementary Files. The MOs of the $\mathrm{Rh}_{2}$ core are shown in the two boxes.

coordination of the thiolate ligand. This time, because of the lack of axial symmetry, the $\sigma(164)$ and one of the $\pi^{*}(165)$ MOs rise in energy, now above the $\pi^{*}(163)$ and $\delta^{*}(162)$. The surfaces show that the three residues of the tripeptide, GSinteract strongly with many of the Rh-Rh MOs, and not with the tetraacetate MOs. For example, of the highest lying occupied MOs, only $\pi^{*}(163), \delta^{*}(162)$, and $\delta(155)$ do not have significant contribution from the GS- MOs. MOs 159, 160, and 156 are located mainly on the GS- The extensive overlap of the GSdensity with the Rh-Rh core MOs accounts for the retention of the GS- coordination of the $\mathrm{Rh}_{2}(\mathrm{OAc})_{4}$ complex in the ESI-mass spectrometer under the dehydrating conditions (Figure 4).

Figure $7 \mathrm{~B}$ shows the results of the calculations for $\left[\mathrm{Rh}_{2}(\mathrm{OAc})_{4}\left(\mathrm{GS}^{-}\right)_{2}\right]^{2-}$. Again, $\sigma(241)$ rises above the $\pi^{*} \operatorname{MOs}(239$; $240)$ as an effect of the increased density donated by the strongly basic thiolate. With two GS- there is significant overlap of the MOs of the tripeptide with all the Rh-Rh core MOs shuffling the energy stack considerably. MOs 242-232 are located on the two GS- ligands. Despite searching down to MO 220 , we could not locate an MO with symmetry characteristics of the $\delta$ (like MO 155 in Figure 7A). The surfaces provide much more detail concerning the overlap of electron density than text can do justice to, so we direct the reader to the Supplementary Data Figures S1-5.

\section{iii) Calculated absorption spectra for $\left[\mathrm{Rh}_{2}(\mathrm{OAc})_{4}\right]$,} $\left[\mathrm{Rh}_{2}(\mathrm{OAc})_{4}\left(\mathrm{H}_{2} \mathrm{O}\right)_{2}\right],\left[\mathrm{Rh}_{2}(\mathrm{OAC})_{4}\left(\mathrm{GS}^{-}\right)\left(\mathrm{H}_{2} \mathrm{O}\right)\right]^{-}$, and $\left[\mathrm{Rh}_{2}(\mathrm{OAC})_{4}(\mathrm{GS})_{2}\right]^{2-}$

Figure $8 \mathrm{~A}$ shows the calculated absorption spectra, labelled with the Excited States (ES) that show significant oscillator strength (a list of the excited states are available in the 
Supplementary Information). Figure 8B shows the molecular orbital contributions to each excited state.

TD-DFT calculations were carried out for the four complexes described above, however, as the only two that we are confident we have optical data for are the bisaquated and the mono-adducted GS-, we only describe those results here. The full results for the calculations between 900 and $200 \mathrm{~nm}$ are shown in Table Supp-XX with the resulting spectral data shown in Figure 8. The data in Figure 1 identify two visible region bands for the bisaquated complex, at 448 and $589 \mathrm{~nm}$ before intense absorbance below $300 \mathrm{~nm}$ giving these solutions a sky blue colour. The calculations predict bands at 549 and $537 \mathrm{~nm}$, and 397 and $389 \mathrm{~nm}$, with a much more energetic and intense band at $238 \mathrm{~nm}$. The relative intensities and band energies are reproduced very closely by the calculations. The calculation for the bisaquated complex (Figure 7) shows that the visible region bands arise from pairs of transitions that add contributions from each of the Rh $4 \mathrm{~d}$ orbital set. We have added symmetry labels to allow the mixing to be seen clearly. The $\delta^{*} \mathrm{MO}$ does not contribute significantly to any absorption. The absorption is essentially purely the Rh core offset by the electron density from the two waters.

\begin{tabular}{|c|c|c|c|}
\hline $\mathrm{Rh}_{2}(\mathrm{OAc})_{4}$ & $\begin{array}{l}\text { Rh-Rh } \\
\text { bond } \\
\text { length } \\
\text { /A }\end{array}$ & $\mathrm{E}(\sigma) / \mathrm{eV}$ & $\mathrm{E}\left(\sigma^{*}\right) / \mathrm{eV}$ \\
\hline \multicolumn{4}{|l|}{$\left[\mathrm{Rh}_{2}(\mathrm{OAc})_{4}\left(\mathrm{H}_{2} \mathrm{O}\right)_{2}\right]$} \\
\hline \multicolumn{4}{|l|}{$\begin{array}{l}{\left[\mathrm{Rh}_{2}(\mathrm{OAc})_{4}\left(\mathrm{GS}^{-}\right.\right.} \\
\left.)\left(\mathrm{H}_{2} \mathrm{O}\right)\right]^{-}\end{array}$} \\
\hline$\left[\mathrm{Rh}_{2}(\mathrm{OAc})_{4}\left(\mathrm{GS}^{-}\right)_{2}\right]^{2-}$ & & & \\
\hline
\end{tabular}

Origins of the electronic absorption spectrum of $\left[\mathrm{Rh}_{2}(\mathrm{OAc})_{4}\left(\mathrm{H}_{2} \mathrm{O}\right)_{2}\right]$ The bisaquated dirhodium tetraacetate is a sky blue colour in solution with the lowest energy band at $589 \mathrm{~nm}$, Figure 1. The TD-DFT results (Figure 8 ) assign this band to a mixture of transitions from the $\pi^{*}$ and $\sigma(86,87, \& 88)$ to the $\sigma^{*}(90)$ and MO 91, but not from the $\delta^{*}(89)$ because of application of selection rules. However, the major contribution to the oscillator strength is from $\pi^{*}(88)$ to $\sigma^{*}(90)$. The theoretical absorption spectrum (Figure $8 \mathrm{~A}$ ) shows the presence of three distinct absorption bands (labelled ES1/2, ES3/4, ES5) that arise from pairs of transitions involving all the dirhodium MOs as shown in Figure 8B. The predominant transition remain $\pi^{*}$ to $\sigma^{*}$ for the visible region bands. The lack of strong absorption between 500 and $300 \mathrm{~nm}$ accounts for the blue solution spectra. The ES3/4 can be seen in the absorption spectrum at $448 \mathrm{~nm}$ (Figure 1). These four transitions all involve a significant contribution from the acetate-Rh MOs. However, ES5 is strongly connected with a $\sigma(86)$ to $\sigma^{*}(90)$ transition, which involves the two coordinated waters and not the acetates.

Origins of the electronic absorption spectrum of $\left[\mathrm{Rh}_{2}(\mathrm{OAC})_{4}\left(\mathrm{GS}^{-}\right)\left(\mathrm{H}_{2} \mathrm{O}\right)\right]^{-}$
Addition of thiols results in a yellow colouration (Figure 1) arising from the increase in absorption at $353 \mathrm{~nm}$. The calculated results for the mono-thiolate (Figure $8 \mathrm{~A}$ and $\mathrm{B}$ ) show the presence of new transitions in the visible and near-UV regions. The calculations again place the lowest energy transition near $600 \mathrm{~nm}$, as seen in the experimental spectrum, but now introduce a series of bands, mostly very weak, but with the most intense new band being at $326 \mathrm{~nm}$ (ES5). These bands result from charge transfer from GS-dominated MOs to the $\sigma^{*}$ (166) $\mathrm{Rh}_{2}$ core MO. By plotting the theoretical spectrum with realistic band widths we show the origins of the shoulder in Figure 1 as the GSH is added. The CD spectrum Figure 2, indicates the asymmetry introduced by the chiral GS- binding to the $\mathrm{Rh}_{2}$ core between 250 and $370 \mathrm{~nm}$, a region associated in the calculations with bands at 321 and $326 \mathrm{~nm}$.

\section{The theoretical electronic absorption spectrum of $\left[\mathrm{Rh}_{2}(\mathrm{OAc})_{4}\left(\mathrm{GS}^{-}\right)_{2}\right]^{2-}$}

The calculation for the di-GS2- shows an increase in the chargetransfer transition below $400 \mathrm{~nm}$ (Figure 8, ES3-8) and the blueshift of the lowest energy transition near $530 \mathrm{~nm}$ (ES1) is associated with stronger contributions from both coordinated glutathiones.

\section{Conclusions}

Glutathione is well known as a strongly coordinating molecule that exists in high cellular concentration. It is upregulated in homeostatic response to soft and potentially toxic metals. In the results described above, we report that glutathione binds to $\mathrm{Rh}_{2}(\mathrm{OAc})_{4}$, forming primarily the mono-adduct with retention of the single Rh-Rh bond. This means that glutathione binds axially and does not disrupt the intended, therapeutically-important, structure, but does block one of the axial sites. In the cellular milieu, this may mean that dirhodium carboxylates can survive and retain their anti-cancer activity. The computational calculations provide insight into the extensive overlap of the glutathione molecular orbitals with the $\mathrm{Rh}_{2}(\mathrm{OAc})_{4}$ core orbitals, providing interpretation of the strength of the glutathione cysteine thiolate-rhodium bond. The calculations also allow an understanding of the optical spectral properties, showing how the introduction of axial ligands introduce new, strong absorption in the $300-400 \mathrm{~nm}$ region, and blue-shifting the lowest energy band at 500-600 $\mathrm{nm}$. The presence of the axial ligand provides a significant charge transfer to each of the optical transitions. The calculated MO energies for the four species studied show that the presence of the axial ligand is to destabilize all orbitals as a result of the introduction electron density onto the rhodium core. Significantly, the relative energy of $\mathrm{Rh} \sigma$ is raised with respect to $\delta$ and $\pi$. Despite the extensive overlap of the glutathione orbitals with the Rh MO, the acetate linker MOs remain largely unaffected, which accounts for the observation that the acetates are retained following axial coordination with GSH. 
We have shown in a previous report that the cysteine-rich metallothionein protein not only binds $\mathrm{Rh}_{2}(\mathrm{OAc})_{4}$, but sequentially deconstructs the complex by replacing the four carboxylate ligands with the metallothionein cysteine thiolates ${ }^{48}$. In this case, the $\mathrm{Rh}_{2}(\mathrm{OAc})_{4}$ would be deactivated. Metallothionein has long been associated with a detoxification role, and this reaction with $\mathrm{Rh}_{2}(\mathrm{OAc})_{4}$ is just one example of this property. However, glutathione is present in at least 100 times greater concentration in the cytoplasm than metallothionein. We suggest, based on the results presented here, that a major feature in the design for these therapeutic rhodium carboxylates should be the incorporation of weakly coordinated sulfur at the axial position of the dirhodium core. If such groups were included in the overall design, the results presented above suggest that the complex could remain intact longer in the cell and be somewhat protected against rapid metabolic deconstruction.

Metallodrugs offer a future of tunable therapeutic complexes that will be applicable to a large number of diseased states; well-known examples include Platinol $(\mathrm{Pt})$, Ridaura $(\mathrm{Au})$, and Trisenox (As) ${ }^{59}$. For the drug to be effective, the delivered form of the metal complex must be as designed. Pro-drugs are designed to change, following metabolism, into the active therapeutic agent, in which case the metabolic pathways must be well known. In other cases, it is assumed that the metallocomplex will be unchanged following passage into the cell. The plasma and cellular cytoplasm contain coordinating biomolecules that will bind tightly to these xenobiotic metals that form the therapeutic complex, changing the complex's properties. If this change significantly alters their therapeutic activity, then this drug has no value, and may result in higher toxicity. Understanding the potential coordination chemistry that can take place in either the plasma or the cytoplasm is important in the design and subsequent application of these drugs. Our data confirm the view that the dirhodium(II) tetracetate could easily targeted by the intracellular thiols like glutathione, but could be protected by weak axial ligands, and still be able to bind to their intended biological targets.

\section{Experimental Methods}

Solutions of $500 \mu \mathrm{M} \mathrm{Rh}(\mathrm{OAc})_{4}$ (Sigma Aldrich) and $10 \mathrm{mM}$ glutathione (Fluka) in deionized water were deoxygenated under vacuum and backfilled with argon gas. For the UV-visible (Varian Cary 50 UV-Visible Spectrophotometer) and circular dichroism (Jasco 810 Spectropolarimeter) spectroscopic measurements, aliquots of $0,0.5,1.0,1.5,2.0$, and 2.5 , mol. eq. (and additionally, 3.0, and $4.0 \mathrm{~mol}$. eq. for the UV-visible absorption spectra) of GSH were added to an argon-backfilled quartz cuvette sealed with a septum cap containing the dirhodium solution, with the data recorded after each addition. For the first ESI-MS data collection (Figure 3), a $600 \mu \mathrm{M} \mathrm{GSH}$ solution was titrated with $2 \mathrm{~mol}$. eq. $\mathrm{Rh}_{2}(\mathrm{OAc})_{4}$ and the mass spectral data were collected in positive ion mode; in the second series (Figure 4), solutions with $500 \mu \mathrm{M} \mathrm{Rh}_{2}(\mathrm{OAc})_{4}$ were titrated with 1.0, 1.5, and $2.5 \mathrm{~mol}$. eq. $500 \mu \mathrm{M} \mathrm{GSH}$ in $1 \mathrm{mM} \mathrm{NH}_{4} \mathrm{OAc}$ buffer at $\mathrm{pH} 7.4$, recorded in both positive and negative ion mode. A Bruker Micro-TOF II instrument (Bruker Daltonics, Toronto, ON) operated in the positive ion mode was used to collect the data. Nal was used as an external calibrant. The following settings were used: scan, $\mathrm{m} / \mathrm{z}$ 50-3000; rolling average, 2; nebulizer, 2 bar; dry gas, $80^{\circ} \mathrm{C}$ at a rate of $8.0 \mathrm{~L} / \mathrm{min}$; capillary, $4000 \mathrm{~V}$; end plate offset, $-500 \mathrm{~V}$; capillary exit, $175 \mathrm{~V}$; skimmer 1, $30.0 \mathrm{~V}$; skimmer 2, $23.5 \mathrm{~V}$; hexapole RF, $800 \mathrm{~V}$.

For the reactions with methionine followed by competition with $\mathrm{GSH}$, solutions of $500 \mu \mathrm{M} \mathrm{Rh}{ }_{2}(\mathrm{OAc})_{4}$ (Sigma Aldrich), $10 \mathrm{mM} \mathrm{DL-}$ methionine (Sigma), and $10 \mathrm{mM}$ glutathione (Fluka) in deionized water were deoxygenated under vacuum and backfilled with argon gas. The changes in the $\mathrm{Rh}_{2}(\mathrm{OAc})_{4}$ solution were monitored following the addition of $2 \mathrm{~mol}$. eq. of methionine using UV-visible spectroscopy, followed by a subsequent addition of 2 mol. eq. of GSH. ESI-mass spectra were taken after each addition using the negative ion mode. The settings were similar to those described previously.

$\mathrm{Rh}_{2}(\mathrm{OAC})_{4}, \quad \mathrm{Rh}_{2}(\mathrm{OAc})_{4}\left(\mathrm{H}_{2} \mathrm{O}\right)_{2}, \quad \mathrm{Rh}_{2}(\mathrm{OAc})_{4}(\mathrm{GS})\left(\mathrm{H}_{2} \mathrm{O}\right)$, and $\mathrm{Rh}_{2}(\mathrm{OAC})_{4}(\mathrm{GS})_{2}$, models were drawn in Scigress, where GS represents the deprotonated glutathione moiety. Ground-state geometry optimization and TD-DFT were performed with the Gaussian G09 program, using the CAM-B3LYP functional. The 6$31 \mathrm{G}(\mathrm{d}, \mathrm{p})$ basis set was used for all atoms except for $\mathrm{Rh}$, and the LANL2DZ basis set was used for Rh atoms.

\section{Acknowledgements}

We acknowledge financial support from the Natural Sciences and Engineering Research Council of Canada through a Discovery Grant to M. J. S, and from the Ontario Government for providing the Ontario Graduate Scholarship to D. L. W. We would also like to thank Dr. Farideh Jalilehvand (University of Calgary) for initial discussions, Dr A. Faponle, Dr. Sam de Visser, at the University of Manchester, UK for preliminary calculations, and Doug Hairsine (UWO) for expert technical support.

\section{References}

1. P. Nicotera and S. Orrenius, in Biological Reactive Intermediates III, eds. J. J. Kocsis, D. J. Jollow, C. M. Witmer, J. O. Nelson and R. Snyder, Springer, New York, 1986, pp. 41-51.

2. A. Meister and M. E. Anderson, Annu. Rev. Biochem., 1983, 52, 711-760.

3. B. A. Arrick and C. F. Nathan, Cancer Res., 1984, 44, 42244232.

4. F. Zunino, G. Pratesi, A. Micheloni, E. Cavalletti, F. Sala and O. Tofanetti, Chem.-Biol. Interact., 1989, 70, 89-101.

5. N. Traverso, R. Ricciarelli, M. Nitti, B. Marengo, A. L. Furfaro, M. A. Pronzato, U. M. Marinari and C. Domenicotti, Oxid. Med. Cell Longev., 2013, 2013.

6. H. J. Forman, H. Zhang and A. Rinna, Mol. Aspects Med., 2009, 30, 1-12. 
7. G. K. Balendiran, R. Dabur and D. Fraser, Cell Biochem. Funct., 2004, 22, 343-352.

8. D. M. Townsend and K. D. Tew, Oncogene, 2003, 22, 73697375.

9. D. M. Townsend, K. D. Tew and H. Tapiero, Biomed. Pharmacother., 2003, 57, 145-155.

10. S. Goto, T. lida, S. Cho, M. Oka, S. Kohno and T. Kondo, Free Radical Res., 1999, 31, 549-558.

11. K. D. Tew, Cancer Res., 1994, 54, 4313-4320.

12. A. Albert, C. Brauckmann, F. Blaske, M. Sperling, C. Engelhard and U. Karst, J. Anal. Atom. Spectrom., 2012, 27, 975-981.

13. A. Meister, J. Biol. Chem., 1994, 269, 9397-9400.

14. M. E. Anderson, A. Naganuma and A. Meister, FASEB J., 1990, 4, 3251-3255.

15. G. Noctor and C. H. Foyer, Annu. Rev. Plant. Biol., 1998, 49, 249-279.

16. J. K. C. Lau and D. V. Deubel, Chem.-Eur. J., 2005, 11, 2849 2855.

17. A. Casini, A. Karotki, C. Gabbiani, F. Rugi, M. Vašák, L. Messori and P. J. Dyson, Metallomics, 2009, 1, 434-441.

18.

19.

20. V. Mah and F. Jalilehvand, J. Biol. Chem., 2008, 13, 541-553. V. Mah and F. Jalilehvand, J. Biol. Chem., 2010, 15, 441-458. V. Mah and F. Jalilehvand, Chem. Res. Toxicol., 2010, 23, 1815-1823.

21. V. Mah and F. Jalilehvand, Inorg. Chem., 2012, 51, 62856298.

22. N. Scott, K. M. Hatlelid, N. E. MacKenzie and D. E. Carter, Chem. Res. Toxicol., 1993, 6, 102-106.

23. B. O. Leung, F. Jalilehvand, V. Mah, M. Parvez and Q. Wu, Inorg. Chem., 2013, 52, 4593-4602.

24. E. Volckova, L. P. Dudones and R. N. Bose, Pharm. Res. 2002, 19, 124-131.

25. S. Goto, K. Yoshida, T. Morikawa, Y. Urata, K. Suzuki and T. Kondo, Cancer Res., 1995, 55, 4297-4301.

26. N. Burford, M. D. Eelman, D. E. Mahony and M. Morash, Chem. Commun., 2003, 146-147.

27. A. K. Godwin, A. Meister, P. J. O'Dwyer, C. S. Huang, T. C. Hamilton and M. E. Anderson, P. Natl. Acad. Sci., 1992, 89, 3070-3074.

28. S.-I. Hamada, M. Kamada, H. Furumoto, T. Hirao and T. Aono, Gynecol. Oncol., 1994, 52, 313-319.

$29 . \quad$ R. A. Hromas, P. A. Andrews, M. P. Murphy and C. P. Burns, Cancer Lett., 1987, 34, 9-13.

30.

P. A. Andrews, M. A. Schiefer, M. P. Murphy and S. B. Howell, Chem.-Biol. Interact., 1988, 65, 51-58.

31. C. M. Rudin, Z. Yang, L. M. Schumaker, D. J. VanderWeele, K. Newkirk, M. J. Egorin, E. G. Zuhowski and K. J. Cullen, Cancer Res., 2003, 63, 312-318.

32. A. Erck, E. Sherwood, J. Bear and A. Kimball, Cancer Res., 1976, 36, 2204-2209.

33. R.-A. Howard, T. Spring and J. Bear, Cancer Res., 1976, 36, 4402-4405.

34. K. Sorasaenee, P. K.-L. Fu, A. M. Angeles-Boza, K. R. Dunbar and C. Turro, Inorg. Chem., 2003, 42, 1267-1271.

35. A. M. Angeles-Boza, H. T. Chifotides, J. D. Aguirre, A. Chouai, P. K.-L. Fu, K. R. Dunbar and C. Turro, J. Med. Chem., 2006, 49, 6841-6847.

36.

A. Dorcier, W. H. Ang, S. Bolano, L. Gonsalvi, L. JuilleratJeannerat, G. Laurenczy, M. Peruzzini, A. D. Phillips, F. Zanobini and P. J. Dyson, Organometallics, 2006, 25, 40904096.
37.

38.

39.

40

41

42.

44.

45.

46.

47.

48.

49

50.

51.

52.

53.

54.

55.

56.

57.

58.

59. I. Romero-Canelón and P. J. Sadler, P. Natl. Acad. Sci., 2015, $112,4187-4188$.

F. P. Pruchnik, R. Starosta, Z. Ciunik, A. Opolski, J. Wietrzyk, E. Wojdat and D. Dus, Can. J. Chem., 2001, 79, 868-877.

F. Pruchnik and D. Duś, J. Inorg. Biochem., 1996, 61, 55-61. R. Głaszczka, J. Jaźwiński, B. Kamieński and M. Kamińska, Tetrahedron-Asymmetr., 2010, 21, 2346-2355. oncology/hematology, 2002, 42, 297-308.

R. Głaszczka and J. Jaźwiński, Journal of Coordination Chemistry, 2016, 69, 3703-3714.

G. Gasser, I. Ott and N. Metzler-Nolte, J. Med. Chem., 2010, 54, 3-25.

E. B. Boyar and S. D. Robinson, Coordin. Chem. Rev., 1983, 50, 109-208.

L. Trynda and F. Pruchnik, J. Inorg. Biochem., 1995, 58, 6977.

B. Desoize, Anticancer Res., 2004, 24, 1529-1544.

H. T. Chifotides and K. R. Dunbar, Accounts Chem. Res., 2005, 38, 146-156.

P. Jakimowicz, L. Ostropolska and F. P. Pruchnik, Metal Based Drugs, 2000, 7. 5698-5701.

A. Presta and M. J. Stillman, Chirality, 1994, 6, 521-530.

G. Pneumatikakis and P. Psaroulis, Inorganica Chimica Acta, 1980, 46, 97-100.

F. Cotton, B. DeBoer, M. LaPrade, J. Pipal and D. Ucko, Acta Crystallographica Section B: Structural Crystallography and Crystal Chemistry, 1971, 27, 1664-1671. 804.

J. G. Norman Jr and H. J. Kolari, Journal of the American Chemical Society, 1978, 100, 791-799.

G. Christoph and Y. Koh, Journal of the American Chemical Society, 1979, 101, 1422-1434. Journal of the American Chemical Society, 1989, 111, 81568160. Inorg. Chem., 1979, 18, 475-478.

V. M. Miskowski, W. P. Schaefer, B. S. Sadeghi, B. D. Santarsiero and H. B. Gray, Inorg. Chem., 1984, 23, 11541162.

Z. k. Futera, T. s. Koval, J. Leszczynski, J. Gu, M. Mitoraj, M. Srebro and J. V. Burda, The Journal of Physical Chemistry A, 2011, 115, 784-794 